\title{
Optimal Placement of Different Types of Dg Sources in Distribution Networks Using Pso Algorithm and Differential Evolution
}

\author{
J. Adeline Sneha ${ }^{\# 1}$, K. Kumar ${ }^{\# 2}$, V. Bens Joie Victor ${ }^{\# 3}$, J. Aran Glenn ${ }^{\# 4}$ \\ ${ }^{\# 1}$ Lecturer, EIE Department, Sathyabama University, Chennai, Tamil Nadu, India \\ \#2 Assistant Professor, EIE Department, Sathyabama University, Chennai, Tamil Nadu, India \\ ${ }^{\# 3}$ PG Scholars, G.K.M College of Engineering and Technology, Chennai, Tamil Nadu, India \\ ${ }^{\# 4}$ Associate Engineers, Cognizant Technology Solutions, Chennai, Tamil Nadu, India
}

\begin{abstract}
In the present work the optimal placement of different types of DGs has been proposed. The optimal locations and size of the DG's have been determined by minimizing the power distribution loss. The optimal power factor for DG supplying, both real and reactive power, has been obtained in this work. Different types of DGs supplying real and reactive power at different buses have also been considered in the proposed approach. The particle swarm optimization (PSO) technique has been used to solve the optimal placement of DGs. The results obtained from the PSO technique have also been compared with the analytical approach results. The proposed technique is tested on 33-bus test system. Also total power loss can be found out by using differential evolution.
\end{abstract}

Index Terms: Analytical expressions, distributed generation (DG), loss reduction, optimal location, optimal power factor, optimal size, PSO Algorithm, Differential Evaluation.

\section{Introduction}

Currently, most of the power systems generate and supplies electricity having into account the following considerations:

$>$ Electricity generation is produced in large power plants, usually located close to the primary energy source and far away from the consumer centres.

$>$ Electricity is delivered to the customers using a large passive distribution infrastructure, which involves high voltage (HV), medium voltage (MV) and low voltage (LV) networks.

$>$ These distribution networks are designed to operate radially. The power flows only in one direction: from upper voltage levels down-to customers situated along the radial feeders.

$>$ In this process, there are three stages to be passed through before the power reaching the final user, i.e. generation, transmission and distribution

In the first stage the electricity is generated in large generation plants, located in non- populated areas away from loads to get round with the economics of size and environmental issues. Second stage is accomplished with the support of various equipments such transformers, overhead transmission lines and underground cables. The last stage is the distribution, the link between the utility system and the end customers. This stage is the most important part of the power system, as the final power quality depends on its reliability.

In the first stage the electricity is generated in large generation plants, located in non- populated areas away from loads to get round with the economics of size and environmental issues. Second stage is accomplished with the support of various equipments such transformers, overhead transmission lines and underground cables. The last stage is the distribution, the link between the utility system and the end customers. This stage is the most important part of the power system, as the final power quality depends on its reliability.

\section{New Concept Of Power Systems}

Nowadays, the technological evolution, environmental policies, and also the expansion of the finance and electrical markets, are promoting new conditions in the sector of the electricity generation.

New technologies allow the electricity to be generated in small sized plants. Moreover, the increasing use of renewable sources in order to reduce the environmental impact of power generation leads to the development and application of new electrical energy supply schemes. 


\section{Proposed Methodology}

\section{A. Problem Formulation}

The optimal sizing and placement of DG results in minimum loss in the distribution system[11].The total real Loss in a distribution system is given by:

$\mathrm{P}_{\text {losses }}=\sum_{\mathrm{i}=1}^{\mathrm{N}}\left|\mathrm{I}_{\mathrm{i}}^{2}\right| \mathrm{R}_{\mathrm{i}}(4.1)$

where $I_{i}$ is the current magnitude of each branch and $R_{i}$ is the resistance of ith branch. considering $N$ bus distribution systems, the loss minimization may be formulated as given below:

$\operatorname{Minimize}_{\mathrm{l}}=\sum_{\mathrm{i}}^{\mathrm{N}} \sum_{\mathrm{j}}^{\mathrm{N}}\left[\alpha_{\mathrm{ij}}\left(\mathrm{P}_{\mathrm{i}} \mathrm{P}_{\mathrm{j}}+\mathrm{Q}_{\mathrm{i}} \mathrm{Q}_{\mathrm{j}}\right)+\beta_{\mathrm{ij}}\left(\mathrm{Q}_{\mathrm{i}} \mathrm{P}_{\mathrm{j}}-\mathrm{P}_{\mathrm{i}} \mathrm{Q}_{\mathrm{j}}\right)\right]$

where $_{\mathrm{ij}}=\frac{\mathrm{R}_{\mathrm{ij}}}{\mathrm{V}_{\mathrm{i}} \mathrm{V}_{\mathrm{j}}} \cos \left(\delta_{\mathrm{i}}-\delta_{\mathrm{j}}\right)$

$\beta_{\mathrm{ij}}=\frac{\mathrm{R}_{\mathrm{ij}}}{\mathrm{V}_{\mathrm{i}} \mathrm{V}_{\mathrm{j}}} \sin \left(\delta_{\mathrm{i}}-\delta_{\mathrm{j}}\right)$

and

$\mathrm{Z}_{\mathrm{ij}}=\mathrm{R}_{\mathrm{ij}}+\mathrm{j} \mathrm{X}_{\mathrm{ij}}$

where

$\mathrm{Z}_{\mathrm{ij}}$ is the impedance of the line between bus $\mathrm{i}$ and bus $\mathrm{j}$;

$\mathrm{R}_{\mathrm{ij}}$ is the resistance of the line between bus $\mathrm{i}$ and bus $\mathrm{j}$;

$V_{i}$ is the voltage magnitude at bus $i$;

$V_{j}$ is the voltage magnitude at bus $\mathrm{j}$;

$\delta_{\mathrm{i}}$ is the voltage angle at bus $\mathrm{i}$;

$\delta_{j}$ is the voltage angle at bus $j$;

$P_{i}$ and $Q_{i}$ is the active and reactive power injection at bus $i$;

$P_{j}$ and $Q_{j}$ is the active and reactive power injection at bus $j$;

Subject To The Constraints:

Another significant part of the optimization model that needs to be defined is the constraints. There are two types of constraints they are

1.Equality Constraints

2.Inequality Constraints

1).Equality Constraints:

These constraints are related to the nonlinear power flow equations.

$\mathrm{P}_{\mathrm{i}}=\mathrm{P}_{\mathrm{DGi}}-\mathrm{P}_{\mathrm{Di}}$

$Q_{\mathrm{i}}=\mathrm{Q}_{\mathrm{DGi}}-\mathrm{Q}_{\mathrm{Di}}$

where

$P_{D G i}$ and $Q_{D G i}$ are real and reactive power injection from DG is placed at node $\mathrm{i}$.

$\mathrm{P}_{\mathrm{Di}}$ and $\mathrm{Q}_{\mathrm{Di}}$ are the load demand at node $\mathrm{i}$.

2).Inequality constraints

The Inequality constraints are those associated with bus voltages and DG to be installed.

(a)Bus Voltage Limit:

The bus voltage magnitudes are to be kept within acceptable operating limits throughout the optimization process.

$V_{\min } \leq V_{i} \leq V_{\max }$

where

$V_{\text {min }}$ is Lower bound of bus voltage limits.

$V_{\mathrm{i}}$ is RMS value of the bus voltage.

$V_{\max }$ is Upper bound of bus voltage limits.

(b)Number and sizes of DGs:

These are constraints related with the DG and themselves. DGs that are commercially available come in discrete sizes. The total real power losses of the system is minimum with respect to injected power is zero with partial derivative of Equation (4.1).

It follows that

$\mathrm{P}_{D G i}=\mathrm{P}_{D i}-\frac{1}{\alpha_{\mathrm{ii}}}\left[\sum_{\mathrm{j}=1}^{\mathrm{N}} \sum_{\mathrm{j} \neq \mathrm{i}}\left(\alpha_{\mathrm{ij}} \mathrm{P}_{\mathrm{j}}-\beta_{\mathrm{ij}} \mathrm{Q}_{\mathrm{j}}\right)\right]$ 
$\mathrm{Q}_{D G i}=Q_{D i}-\frac{1}{\alpha_{\mathrm{ii}}}\left[\sum_{\mathrm{j}=1}^{\mathrm{N}} \sum_{\mathrm{j} \neq \mathrm{i}}\left(\alpha_{\mathrm{ij}} \mathrm{Q}_{\mathrm{j}}+\beta_{\mathrm{ij}} \mathrm{P}_{\mathrm{j}}\right)\right]$

Equations (4.9) and (4.10) can be combined to determine the size of DG. The bus which has an lowest real power loss is considered as the optimal placement for DG followed by satisfactions of constraint.

The power factor may be considered as optimal and represented as:

$$
\mathrm{OPF}=\frac{\mathrm{P}_{\mathrm{DGi}}}{\sqrt{\mathrm{P}_{\mathrm{DGi}}^{2}+\mathrm{Q}_{\mathrm{DGi}}^{2}}}
$$

\section{B. Types of DG}

DG can be classified into four major types based on theirterminal characteristics in terms of real and reactive power deliveringcapability as follows:

1) Type 1: DG capable of injecting $P$ only.

2) Type 2: DG capable of injecting $Q$ only.

3) Type 3: DG capable of injecting both $P$ and $Q$.

4) Type 4: DG capable of injecting $P$ but consuming $Q$.

Photovoltaic, micro turbines, fuel cells, which are integratedto the main grid with the help of converters/inverters are goodexamples of Type 1 . Type 2 could be synchronous compensatorssuch as gas turbines. DG units that are based on synchronousmachine (cogeneration, gas turbine, etc.) fall in Type 3. Type 4is mainly induction generators that are used in wind farms.

\section{Sizing at Various Locations}

Assuming a $=($ sign $) \tan \left(\cos ^{-1}(\right.$ PFDG $\left.)\right)$, the reactive power output of DG is expressed by (2) $\mathrm{QDGi}=\mathrm{aPDGi}(2)$

in which

sign $=+1:$ DG injecting reactive power;

sign $=-1$ : $D G$ consuming reactive power;

PFDG is the power factor of DG.

The active and reactive power injected at bus $i$, where the DG

located, are given by (3) and (4), respectively,

$\mathrm{Pi}=\mathrm{PDGi}-\mathrm{PDi}(3)$

$\mathrm{Qi}=\mathrm{QDG}-\mathrm{QDi}=\mathrm{aPDGi}-\mathrm{QDi}$. (4)

From (1), (3), and (4), the active power loss can be rewritten as

$\operatorname{Minimize}_{l}=\sum_{\mathrm{i}}^{\mathrm{N}} \sum_{\mathrm{j}}^{\mathrm{N}}\left[\alpha_{\mathrm{ij}}\left(\mathrm{P}_{\mathrm{i}} \mathrm{P}_{\mathrm{j}}+\mathrm{Q}_{\mathrm{i}} \mathrm{Q}_{\mathrm{j}}\right)+\beta_{\mathrm{ij}}\left(\mathrm{Q}_{\mathrm{i}} \mathrm{P}_{\mathrm{j}}-\mathrm{P}_{\mathrm{i}} \mathrm{Q}_{\mathrm{j}}\right)\right]$

The power factor of DG depends on operating conditions and type of DG. When the power factor of DG is given, the optimalsize of DG at each bus $i$ for minimizing losses can be found inthe following way.

1) Type 1 DG: For Type 1 DG, power factor is at unity, i.e.,FDG =1, a = 0. From (10), the optimal size of DG at

each bus i for minimizing losses.

2) Type 2 DG: Assuming PFDG $=0$ and $a=\infty$, from (2) to(10), the optimal size of DG at each bus $i$ for minimizing

Losses.

3) Type 3 DG: Assuming $0<$ PFDG $<1$, sign=+1 and "a"is a constant, the optimal size of DG at each bus i for the

minimum loss is given by (10) and (4), respectively.

4) Type 4 DG: Assuming $0<$ PFDG $<1$, sign $=-1$ and "a" is a constant, the optimal size of DG at each bus $i$ for the

minimum loss is given by (10) and (4), respectively.

\section{Optimal Location}

For optimal location, the method proposed in [16] is used.Based on this method, first the optimal sizes at various locationshave been calculated for different types of DG and the losseswere calculated with optimal sizes for each case. The case withminimum losses is selected as the optimal location for each typeof DG. 
Based on this method proposed in [16], one can avoid exhaustivecomputation and save time, especially for large-scale distribution systems as trend of loss reduction can be capturedwith $\alpha$ and $\beta$ coefficients from the bases case. E.

In practice, a complex distribution system includes a fewsources, many buses, many lines and loads. The power factorsof loads are different. If each load is supplied by each local DG,at which the power factor of each DG is equal to that of eachload, there is no current in the lines. The total line power loss is zero. The transmission lines are also unnecessary. However, that is unrealistic since the capital investment cost for DG is toohigh. Therefore, the number of installed DGs should be limited.To find the optimal power factor of DG for a radial complexdistribution system, fast and repeated methods are proposed. Itis interesting to note that in all the three test systems the optimalpower factor of DG (Type 3) placed for loss reduction foundto be closer to the power factor of combined load of respectivesystem.

Fast Approach: Power factor of combined total load ofthe system (PFD ) can be expressed by (13). In this condition, thetotal active and reactive power of the load demand. The "possible minimum" total loss can be achieved if the power factor of DG (PFDG) is quickly selected to be equal tothat of the total load (PFD). That can be expressed by (17)

$\mathrm{PFDG}=\mathrm{PFD}$

\section{F. Computational Procedure}

When power factor ofDGis set to be equal to that of combinedtotal loads, computational procedure to find optimal size andlocation of one of four types ofDG's is described in the following.

Step 1: Run base case load flow without DG.

Step 2: Find base case loss by using equation (4.1)

Step3: Except reference bus find the optimal sizes of DG by using equations (4.9) and (4.10) for minimum distribution loss.

Step 4: Check constraint violation after the placement of DG.

Step 5: Locate optimal bus at which the total loss is minimum corresponding with optimal size at that DG.

Step 6: Calculate power factor using equation (4.11).

Step 7:Run load flow with the optimal size of DG placed at optimal bus.

Step 8: Then calculate exact real power loss after the placement of DG.

\section{Particle Swarm Optimization}

Particle swarm optimization (PSO) is a population-based optimization technique which provides a population-based search procedure in which individuals called particles change their position (state) with time. Particles: These are the entities which move around in a multidimensional search space.

Velocity : Every particle moves in the search space with a velocity associated with it.

Personal Best : During flight, each particle has its own personal best experience (This value is called Pbest).

\section{Conclusion}

The proposed methodology was tested on a distribution system consisting 33 bus test system is shown in figure. By this method the power losses can be minimized and optimal sizes of DG units are calculated at every buses. Also the total power loss can be found out by using differential evolution method. In this study different test systems are used and legalize the result for optimal sizing, placement and power factor. The proposed methods have been developed and simulated in MATLAB environment and to calculate the optimum sizes of DG at various buses and real power and reactive power losses with DG at different locations to identify the best locations. Thus real and reactive power losses is get minimized by the optimal placement of DG. This paper has presented the allocation of different types of DGs using PSO technique for active and reactive power compensation to minimize the real power losses in the primary distribution networks. The optimal power factor has also been determined to minimize the power loss. The results obtained by PSO approach have also been verified using the analytical approach. Since analytical approach evaluates each bus of the system to find the optimal solution, hence it is suitable for finding the location and size of DG in the smaller systems. However in a larger system heuristic approaches are more suitable because searches converge to solution fast. The proposed PSO approach for optimal placement of multiple types of DGs not only reduces the line losses but also minimize the sizes of DGs with satisfaction of the permissible voltage limits. In the age of integrated grid, the placement and analysis of different types of DGs give guidance for optimal operation of power system.

This paper presents analytical expressions to identify the optimal sizing and placement of DG at various locations for different bus systems. The system performance improvement on the system depends largely on where the DG is located. The effect of active power loss has become a major problem because it reduces the 
efficiency of power transfer and deteriorates the voltage profile. The minimization of real power loss in the distribution network is gaining much significance when compared to the transmission system. The optimal placement and sizing of DG units in the existing grid system attempt to reduce the real power loss to a considerable extent. The methodology was tested on 33 bus test system for minimizing the real and reactive power losses. Adding DG to critical bus will improve the system performance most effectively. Analytical approach method is used for the DG installation at the optimal locations and reducing the real power losses of the network. Results shows that the locations, size, of distributed generators are decisive factors in reducing losses.

\section{Future Scope}

Distributed energy systems, including fuel cell, wind turbine, photovoltaic(PV), etc that are connected to the power grid, can provide solution to many power system problems. Distributed generation has proven to effectively improve power system stability, power quality, energy efficiency and help environmental protection. As DG has shown its benefits in the practical world as well as its great promise in the future, we are being increasingly interested in where and how we shall locate the DG, how much improvement could be expected, etc.

The effect varies depending upon the placement of a DG in a network. Therefore it is of great interest to know the optimal placement strategy.

The power loss in transmission line is a big problem in electricity transmission. Although the voltage for power transmission over a long distance is raised to be extremely high value a lot of power is still wasted in the transmission line. DG reduces power loss in an electric power system since it could be located near the load centre and therefore the power transmission distance is reduced.

\section{References}

[1]. Momoh j., Yan Xia, BosewellG.D."An Approach to determine Distributed Generation(DG) benefits in power networks, "Power Symposium, 2008.NAPS, pp 1-7, Sept.(2008).

[2]. Akorede, M.K.,Himaz, H.,Ari, I.,Abkadir, M.Z.A., "Effetive method for optimal allocation of distributed generation units in meshed electric power systems" Generation, Transmission \& Distribution IET Vol.5, Issue:2 pp.276-287 Feb.(2011).

[3]. Chiradeja, Pathomthat and Ramakumar, R "An Aproach to Quntify the technical Benefits of Distributed Generation", IEEE Transaction on Energy Conversion, Vol.19,NO.4, pp.764-773,(2004).

[4]. IEA publications. Distributed generation in liberalized electricity market, 2002. Availablefrom:http://www.iea.org/dbtw-wpd/textbase/nppdf/free/2000/distributed 2002.pdf.

[5]. Acharya N. Mahat p, Mithulananthan N. An analytical approach for DG allocation in primary distribution network. Elect power Energy Syst 2006:28(10):669-78.

[6]. BaranME,Wu FF. Optimum sizing of capacitor placed on radial distribution systems. IEEE Trans PWRD 1989;4:735-743.

[7]. D.P.Kotharicentre for Energy Studies, Indian Instititute of Technology, "Simple and efficient method for load flow solution of radial distribution networks", Electrical power \& Energy Systems, vol. 17,No.5,pp.335-346,1995 copyright (C) 1995 Elsevier Science Ltd.

[8]. See webpage of $<$ http://en.wikipedia.org/wiki/Distributed_generation $>$ (accessed December 2011).

[9]. khoan T, Vaziri M. Effects of dispersed generation(DG) on distribution systems. power Engineering Society General Meeting IEEE_2005;3:2173-8.

[10]. IEEE STANDARD 1547. Interconnecting distributed resources with electric power systems; 2003.

[11]. CIGRE Workgroup C6.01.Development of dispersed generation and consequences for power systems. Final report; July 2003.

[12]. Borges CLT, Falcao DM. Optimal distributed generation allocation for reliability, losses and voltage improvement. International Journal of Electrical power and energy Systems 2006;11(6);413-20.

[13]. Jizhong Zhu, Kwok Cheung, Hwang D, SadjadpourA.Operation strategy for improving voltage profile and reducing system loss. IEEE Transactions on power Delivery 2010;25(1):390-7.

[14]. Guerrero JM, Blaabjerg F, Zhelev T, Hemmes K, Monmasson E, Jemei S, et al. Distributed generation: toward a new energy paradigm, industrial electronics magazine. IEEE 2010; 4(1):52-64.

[15]. Wang C,Nehrir MH. Analytical approaches for optimal placement of distributed generation sources in power systems. IEEE,power Transmission Systems 2004;19(4):2068-76.

[16]. J.Aran Glenn, S.Thangalakshmi, "OPTIMAL ARRANGEMENT OF DIFFERENT TYPES OF DISTRIBUTION GENERATION RESOURCES IN DISTRIBUTION NETWORKS”, International Journal of Innovative Research in Engineering and Science (IJIRES), Issue 3, Volume 3: March 2014.

[17]. J.Aran Glenn, J.AdelineSneha, V.Bens Joie Victor, "INDIRECT FIELD ORIENTED SPEED CONTROL OF AN INDUCTION MOTOR DRIVE USING PSO ALGORITHM", International Journal for Technological Research in Engineering (IJTRE), Issue 11, Volume 1: July 2014.

[18]. J.Aran Glenn, J.AdelineSneha, "INDIRECT FIELD ORIENTED SPEED CONTROL OF AN INDUCTION MOTOR DRIVE USING TAKAGI-SUGENO TYPE OF FUZZY LOGIC CONTROLLER”, International Conference on Emerging Trends in Electrical Engineering and Energy Management (ICETEEEM 2012),Vol 2,No.1,Publication Year: 2012 , Page(s): 263 - 266.

[19]. J.Aran Glenn, K.Kumar, J.AdelineSneha, V.Bens Joie Victor, "TAKAGI - SUGENO FUZZY LOGIC SPEED CONTROL OF AN INDIRECT FIELD ORIENTED CONTROL INDUCTION MOTOR DRIVE USING GENETIC ALGORITHM"International Journal of Innovative Research in Engineering and Science(IJIRES), July 2014

[20]. J.Aran Glenn, K.Kumar, J.AdelineSneha, V.Bens Joie Victor, "A Green Technology for Automobiles - Regenerative Braking Control of Hybrid Cars" in Tran stellar journal publication, August 2014. 